\title{
An Approach on Environmental Sanitation Situation and Toilets Septic Tank Design in Urban Nigeria: A Case Study of Calabar South
}

\section{Odey Emmanuel Alepu ${ }^{1 *}$, Zifu Li ${ }^{1}$, Harrison Odion Ikhumhen ${ }^{1}$, Loissi Kalakodio ${ }^{1}$, Egor Ophine Enang ${ }^{2}$ and Giwa Segun Abdulmoseen ${ }^{3}$}

${ }^{1}$ School of Civil and Environmental Engineering, Beijing Key Laboratory of Resource-Oriented Treatment of Industrial Pollutants, University of Science and Technology Beijing Xueyuan 30, Beijing 100083, PR China

${ }^{2}$ Department of Geography and Environmental Science, University of Calabar, Nigeria

${ }^{3}$ State Key Joint Laboratory of Environment Simulation and Pollution Control, School of Environment, Tsinghua University, Beijing 100084, P.R. China

*Corresponding author: Odey Emmanuel Alepu, School of Civil and Environmental Engineering, Beijing Key Laboratory of Resource-Oriented Treatment of Industrial Pollutants, University of Science and Technology Beijing Xueyuan 30, Beijing 100083, PR China, Tel: +8615652933203; E-mail: lordodey1@yahoo.com

Received date: June 18, 2016; Accepted date: July 05, 2016; Published date: July 12, 2016

Copyright: (c) 2016 Alepu OE, et al. This is an open-access article distributed under the terms of the Creative Commons Attribution License, which permits unrestricted use, distribution and reproduction in any medium, provided the original author and source are credited.

\begin{abstract}
In this study, the research protocol was designed for two key objectives. First, to evaluate the present sanitation situation in the fast growing population of Calabar South Nigeria and to design suitable ecological sanitation toilet septic tanks for 8 occupants household and primary school of over 150 students, as an initial awareness of ecological sanitation toilets system in the area. Results from the study showed that less than $40 \%$ households have access to good toilet system while about $70 \%$ institutions have access to good toilet system. The remaining populations use pit latrines, open toilet system, drainage and nearby rivers. Due to shallow surface water condition of Calabar-South, underground water, and drilled borehole water within every household are easily contaminated by pit latrines and poorly designed septic tanks in the area. To solve these problems, two suitable septic tanks were designed for household and institution to create awareness of the new toilet system. Over 90\% respondent expressed their satisfaction about the new development in toilet septic tank. It was recommended that awareness and implementation of ecological sanitation toilets system be carried out for improved household and institutional sanitation in the area.
\end{abstract}

Keywords: Calabar South Nigeria; Environmental sanitation; Ecological sanitation; Septic tanks; Toilet systems

\section{Introduction}

The need for clean water in Nigeria is widely understood but the importance of appropriate sanitation is not yet recognized [1,2]. In many areas, access to simple toilets facilities seems impossible. In most cases, adequate sanitation remains the responsibility of individual households to provide safe and healthy toilet system. Sanitation covers a broad range of environmental problems including hygiene, drainage, solid waste and excreta disposal [3]. This study focuses on excreta disposal. The minimum standard for household excreta disposal in Nigeria is a hygienic and safe facility. But nationally, estimates show that less than half Nigeria population have access to good toilets system [4]. Due to the growing urban population, some areas like Calabar, Nigeria experiences a lack of adequate and acceptable technologies such as VIP toilets, sanplat latrines and traditional pit latrines. As such, many people living around these areas defecate along nearby bushes, uncompleted buildings, and rivers. It is estimated that about $31 \%$ of people in rural or developing areas resort to inadequate sanitation method and human waste disposals such as rivers or dumpsites and open defecation in bushes [5]. In light of this, Bareh [6] suggested that the best way to provide awareness for environmental problems and promote environmentally responsible behaviour is by increasing the access to environmental education.

Lack of access to good toilet facilities together with poor hygiene practices results in diarrhoea, which is the 2nd largest cause of childhood mortality in Nigeria [7]. Also, lack of access to safe and private toilet facilities in schools affects the performance of students [7]. The benefit of adequate toilet system far outweighs the amount of money used. It is estimated that about 10 million productive days would be achieved if access to good sanitation, toilet system, and water rose to $100 \%$ [8].

Access to adequate toilet and general sanitation system varies in Nigeria, with estimates ranging from $15 \%$ to $80 \%$ in some areas $[9,10]$. Institutional sanitation rates are also very poor, especially in primary schools. There is only one toilet for about 500 students in schools [11]. Due to these problems, the Millennium Development Goal (MDG) targets for sanitation are to halve the problems by 2015, the estimated population without access to suitable sanitation. This means about $70 \%$ of people must have access to good sanitation by 2015. Presently, the country is not heading to meet the MDG's target [4]. Up till 2016, most people still lack access to good toilet system in several parts of the country. However, a good toilet system requires an adequate septic tank.

In Calabar, the current septic tank design practice lack consideration on the quality of influent wastewater and effluent which may subsequently affect the disposal system. The usual practice in this area is to directly connect only toilet wastewater line to the septic tank. Effluents from the septic tank are directly discharged into open water bodies, ditches, and drains. Those connected to pits always over flow. The pits then face the problem of early clogging due to poor design. In this study, a survey was carried out in Calabar south local government area of Cross-river state Nigeria to investigate the present toilet system situation and evaluate the actual number of people that have access to good and modern toilet systems. The research also focuses on designing a suitable toilet system for a single household of 8 people 
and primary school of about 150 students. Response from these will aid the proper establishment of ecological sanitation toilet systems in the area.

\section{Methods of Data Collection}

In this study, the concept of ecological sanitation toilet has been thoroughly reviewed. Several indicators have been used in determining the sanitation situation of Calabar South but only the ones that are necessary and relevant to this case being addressed are used in this research and the respondents are asked to provide their personal evaluations based on experiences in their own lives. The language of the questionnaire was also set to be as basic as possible as some of the respondents are not well versed in the terminologies of environmental engineering. In designing the questionnaire, the two principal areas of concern was encountered in the questionnaire layout. The first was to ensure that the questionnaire is presented in a way that is easy to read with clear instructions to the respondents on how to answer the questions asked in a way that the researcher can interpret and represent without difficulty. The second concern was arranging the questions in such a way that it will not actually influence how respondents answer the questions.

Questionnaire were distributed to 48 households at random locations. To make it more randomly distributed, questionnaires were distributed in Watt market which is the largest market in Calabar and the responses were received after few minutes. The data collection process lasted for a period of about 10 days for households and lasted 16 days for primary schools. Data calculation, analysis, and plotting was done using excel shit. The second part of the research was done by designing toilets septic tanks for a newly built primary school and household in the area. The HRT conditions and other physical parameters of the septic tanks were designed based on the number of students in the school and household and the results were presented.

\section{Results and Discussion}

\section{Toilet system situations in the area}

The results obtained showed that about $35 \%$ of the population on a scale of $100 \%$ only has access to modern toilet system as shown in Figure 1. However, the so-called modern toilet system does not have the dehydrating systems with primary or secondary treatment process. The septic tanks in these areas were not designed based on hydraulic retention time (HRT) that determines the time limit for the liquid to remain in the septic tank and solid retention time (SRT) that determines the time limit for solids (faeces) to remain in the tank. As such, the tanks get filled up before the estimated period and lead to the overflow of faeces and gray water to the nearby drainage. Due to lack of adequate facilities and finances to construct the discussed modern toilet system, most of the house owners (landlords) prefer simple pit latrines for their tenants. About $52 \%$ of the people in this area uses pit latrine as recorded from the survey, while $9 \%$ use open toilet system because of unsure hygiene conditions of pit latrines and $4 \%$ of the respondents uses all types of toilets depending on where they find themselves.

The lack of adequate sanitation system in this area and another part of the country experiencing rapid growth results in a serious public health problems. One of the causes of this problem is that, at the local level, Nigeria has 774 Local Government Areas (LGA) and is controlled by local councils. These LGAs are responsible for both rural and urban sanitation schemes in their departments and for implementing water, sanitation, and hygiene (WASH) in their areas. However, only a few LGAs have the resources and skills to provide local needs and construct adequate toilet and water systems and most of the LGAs have not implemented WASH departments [10]. Apart from Lagos and Abuja, no urban community has sewerage system and so, sanitation infrastructure and facilities are lacking. Measures to address these situations will be by ensuring that the LGAs meet their local people's demand for adequate sanitation by frequently checking the conditions.

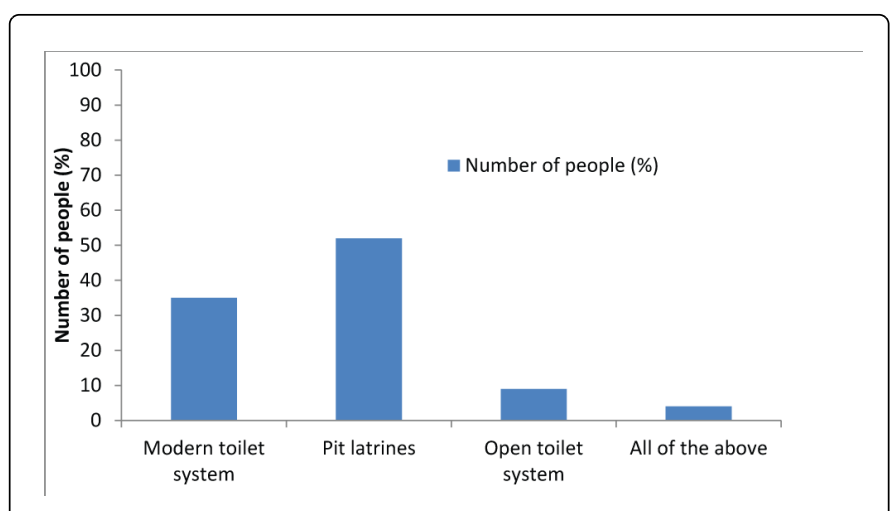

Figure 1: Toilet system survey for households in the area.

In the second scenario, a survey was carried out on 24 primary schools in the area to know the present sanitation and toilet system situations in the various schools and the results are presented in Figure 2. From the results obtained, about $76 \%$ of the students have access to good toilet systems. This is because several nongovernmental organizations (NGOs) are committed to providing adequate toilet system for primary schools. However, some of the modern toilet systems are poorly designed and constructed by local engineers; the schools enjoy these facilities only within a period of about one year due to overflow from septic tanks, forcing some of them to go back to pit latrines. About $14 \%$ of the respondents are currently using pit latrines in the various schools as the management explained that pit latrine is affordable and easy to maintain. 3\% of the students stated that they practice open toilet system, where they go to nearby bushes in the school compound to defecate because they are unsure of the hygiene conditions of the school's toilets, while the remaining $7 \%$ respondent stated that they use any means of toilets system depending on the condition they find themselves. Lack of good toilet system was considered as their least problems. In order to solve the various sanitation issues, suitable and properly designed ecological sanitation septic tank was designed for a single school and a household to improve the toilet systems in these areas. 
Citation: $\quad$ Alepu OE, Li Z, Ikhumhen HO, Kalakodio L, Enang EO, et al. (2016) An Approach on Environmental Sanitation Situation and Toilets Septic Tank Design in Urban Nigeria: A Case Study of Calabar South. Int J Waste Resour 6: 232. doi:10.4172/2252-5211.1000232

Page 3 of 5

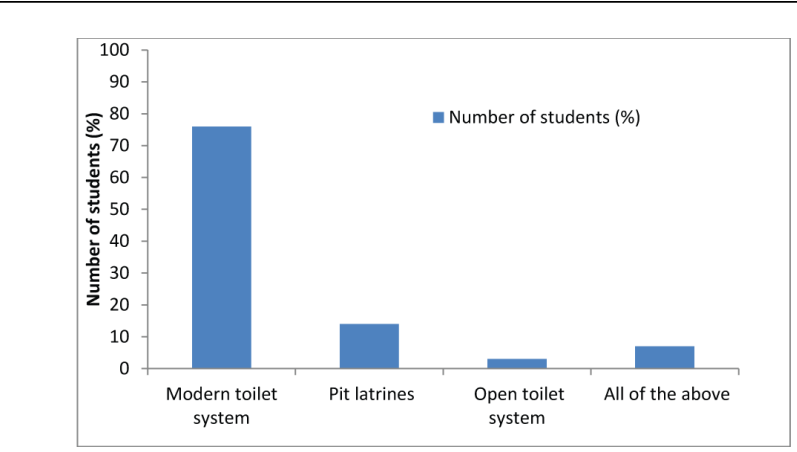

Figure 2: Toilet system survey from institutions in the area.

\section{An approach on toilet septic tank design}

The second approach on this study was to design a septic tank suitable for a household with up to eight occupants in Calabar south in which the houses have full plumbing system. This was done in one of the newly built houses with approximately eight occupants. The septic tank was designed such that all household wastes go to the septic tank and the nominal water supply is $150 \mathrm{~L}$ per person per day. Water is used for anal cleaning, bathing, hand wash and the ambient temperature in this area is not less than $25^{\circ} \mathrm{C}$ for most of the year. The SRT was designed in a way that $24 \mathrm{~h}$ retention is sufficient for the sludge; this duration corresponds to the number of occupants and how often they use toilets and bathroom. The following steps were used to design the suitable septic tank for the selected household:

Stage 1: Volume of liquid entering the tank each day

$\mathrm{A}=\mathrm{P} \times \mathrm{q}(1)$

where $\quad A=$ volume of liquid to be stored in the septic tank

$\mathrm{P}=$ number of people using the tank (Q).

$\mathrm{q}=$ sewage flow $=90 \%$ of the daily water consumption per person

$$
\mathrm{q}=0.9 \times \mathrm{Q}=0.9 \times 150(2)
$$

Therefore $\mathrm{A}=8 \times 135=1080$ litres.

Stage 2: The volume of sludge and scum is given by

$\mathrm{B}=\mathrm{P} \times \mathrm{N} \times \mathrm{F} \times \mathrm{S}(3)$

where $\quad B=$ volume of sludge and scum

$\mathrm{P}=$ number of people using the tank

$\mathrm{N}=$ period between dislodging

$\mathrm{F}=$ sizing factor.

$\mathrm{S}=$ sludge and scum accumulation rate.

Assuming $\mathrm{N}$ is 2 years; from, $\mathrm{F}=1.0$; as all wastes go to septic $\operatorname{tank} \mathrm{S}=40 \mathrm{~L}$ per person per year.

Therefore: $\mathrm{B}=8 \times 2 \times 1.0 \times 40=640 \mathrm{~L}$

Stage 3: Total tank volume $=\mathrm{A}+\mathrm{B}=1080+640=1720$ litres $(1.720$ $\left.\mathrm{m}^{3}\right)(4)$

Volume of $\operatorname{tank}(\mathrm{V})=1.5 \times(2 \mathrm{~W}+\mathrm{W}) \times \mathrm{W}(5)$
Thus $4.5 \mathrm{~W}^{2}=1.720 \mathrm{~m}^{3}$

$\mathrm{W}=0.62 \mathrm{~m}$

Therefore:

width of tank $=0.62 \mathrm{~m}$

length of first compartment $\quad=1.24 \mathrm{~m}$

length of second compartment $\quad=0.62 \mathrm{~m}$

Depth of tank from floor to surface of cover slab = liquid depth + freeboard $=1.5+0.3=1.8 \mathrm{~m}$

The final design is shown in Figure 3.
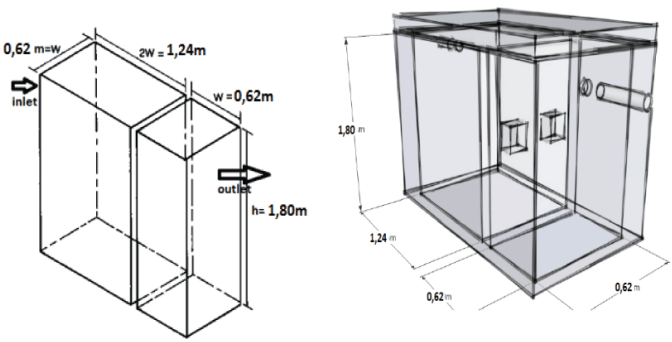

Figure 3: The schematic diagram of the designed septic tank for 8 occupants.

Since septic tanks have sealed walls and floor, the design was properly done to make the tank not flow out of the ground. Flotation may occur if the total mass of the empty septic tank is less than the mass of the water it displaces. This could only happen if the groundwater level is higher than the bottom of the tank. The mass of the wall, floor, and roof were calculated (concrete: $2400 \mathrm{~kg} / \mathrm{m}^{3}$; brickwork: $1500 \mathrm{~kg} / \mathrm{m}^{3}$ ). The volume of the tank was measured (outside dimensions) between the highest groundwater level and the bottom of the tank and was multiplied by the density of water (1000 $\mathrm{kg} / \mathrm{m}^{3}$ ). This gives the mass of water displaced. If the mass of water displaced is greater than the total mass of the empty septic tank then the tank may float. This was prevented by increasing the mass of the structure (by increasing the thickness of the floor and walls) or reducing the amount of the tank that is below the water table. The initial construction of the 8 occupant's household and final construction are shown in Figure $4 \mathrm{a}$ and $4 \mathrm{~b}$.
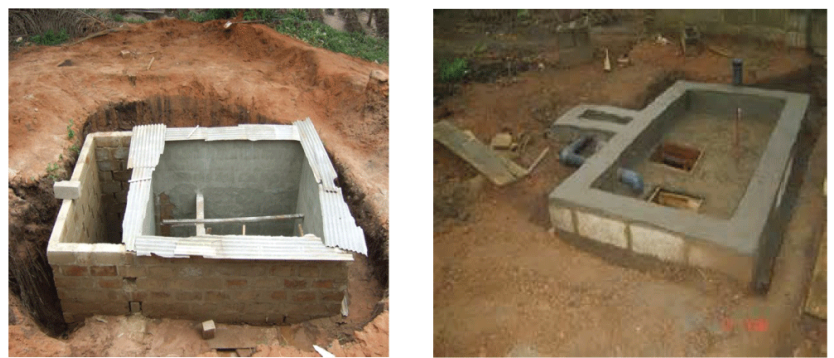

Figure 4: (a) On the left, the building process of the designed septic tank for 8 occupants household and (b) on the right, the final stage. 
Citation: $\quad$ Alepu OE, Li Z, Ikhumhen HO, Kalakodio L, Enang EO, et al. (2016) An Approach on Environmental Sanitation Situation and Toilets

For larger tanks, such as for a school, it is necessary to check that the side walls of the tank are not likely to collapse owing to the outside soil and water pressure. This is most likely when the tank is empty. The second design was for school having 150 students in a medium-density housing area in which the school have full plumbing. Only water closet (WC) wastes go to the septic tank, and paper is used for anal cleaning. The ambient temperature is more than $10^{\circ} \mathrm{C}$ throughout the year. The following steps were used in designing the ecological sanitation toilet systems for the primary school:

Stage 1: Daily volume of liquid

$$
\mathrm{A}=\mathrm{P} \times \mathrm{q}
$$

Where $\mathrm{p}$ is the number of people using the tank, $\mathrm{q}=90 \%$ of the daily water consumption per person (Q).

If the WC has a 10-litre cistern and each person flushes it two times a day, the sewage flow $\mathrm{q}=2 \times 10=20 \mathrm{~L}$ per person per day and $\mathrm{A}=$ $150 \times 20=3000 \mathrm{~L}$

Stage 2: Volume for sludge and scum

$\mathrm{B}=\mathrm{P} \times \mathrm{N} \times \mathrm{F} \times \mathrm{S}$

Assume N is 3 years; $\mathrm{F}=1.0$; as only WC wastes go to septic $\operatorname{tank} \mathrm{S}=25 \mathrm{~L}$ per person per year.

So

$\mathrm{B}=150^{\star} 3^{\star} 1.0^{\star} 25=11,25$ 0liters.

Stage 3: Total tank volume $\mathrm{V}=\mathrm{A}+\mathrm{B}$

$=3000+11,250$

$$
=14,250\left(14.25 \mathrm{~m}^{3}\right)
$$

Stage 4: Assume liquid depth $=1.5 \mathrm{~m}$.

Assume tank width is $\mathrm{W} \mathrm{m}$.

Assume two compartments:

Length of first compartment $(2 \mathrm{~W})=3.56 \mathrm{~m}$

Length of second compartment $(\mathrm{W})=1.78 \mathrm{~m}$

Depth of tank from floor to soffit of cover slab $=1.5 \mathrm{~m}$ (liquid depth) $+0.3 \mathrm{~m}$ (freeboard)

$=1.8 \mathrm{~m}$

In practice the minimum retention time will be greater than 24 hours or the tank will provide longer service than three years before requiring dislodging. The final design and construction of primary school septic tank are shown in Figure 5. Since the designed primary school's septic tank is $14.25 \mathrm{~m}^{3}$, it is approximately equal to or almost the same with $15 \mathrm{~m}^{3}$ size of a septic tank which requires pumping out every 5 years.
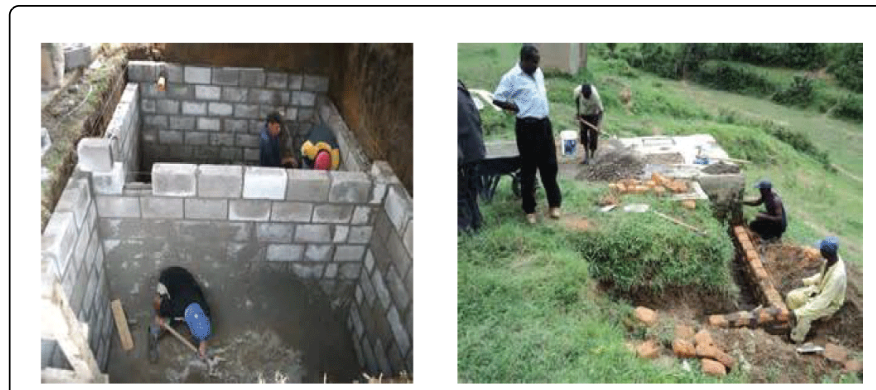

Figure 5: (a) On the left, the building process of the designed septic tank for a selected primary school of 150 students (b) on the right, the completed septic tank.

\section{People's response on the newly designed septic tanks}

As shown in Figure 6a, responses from the 8 occupant's household indicated that over $90 \%$ people were satisfied with the design and hygiene condition of the septic tank. As compared to the previous poorly designed tank, no leakage or odour was observed for the first four months period after construction. About $7 \%$ respondents were unconcerned about the new septic tank because they are not yet sure of the technology, while the remaining $1 \%$ needs more time to check the condition of the toilet system. Drainage and underground water contamination due to septic tank leakage were not observed. This can be attributed to the proper retention time designed and double plastering of the inner wall of the tank.

Figure $6 \mathrm{~b}$ depicts responses from the students on the newly designed septic tank. $90 \%$ of the students who responded to the survey about the designed septic tank expressed satisfaction and further stated that they no longer have to leave the school for the bush to relieve themselves now that the new toilet system is built. $2 \%$ of the respondents were not sure of the new toilets and still prefer their usual open toilet systems. They further suggested that the school management should focus on changing student's behaviour on how everyone uses the toilet in a more hygiene way. Some of them stated that the single most important thing to do to keep from getting sick and to stop the spread of disease-causing germs is to wash your hands with soap often after toilet as taught by their teachers. Most of the respondents suggested that the government and private school owners should adopt the idea and style of the designed septic tank for the entire primary schools in the area.

The school's management suggested that in considering strategic directions for dealing with excreta, consideration should be given to hygiene education, public motivation, and awareness programs, use of small-scale entrepreneurs as faecal sludge treatment operators and septic tank emptier for service operation. On-site sanitation is important and should be used according to local circumstances. Utilities have shown that they can play an important role in improving toilet sanitation issues in institutions [12-16]. 
Citation: $\quad$ Alepu OE, Li Z, Ikhumhen HO, Kalakodio L, Enang EO, et al. (2016) An Approach on Environmental Sanitation Situation and Toilets Septic Tank Design in Urban Nigeria: A Case Study of Calabar South. Int J Waste Resour 6: 232. doi:10.4172/2252-5211.1000232

Page 5 of 5
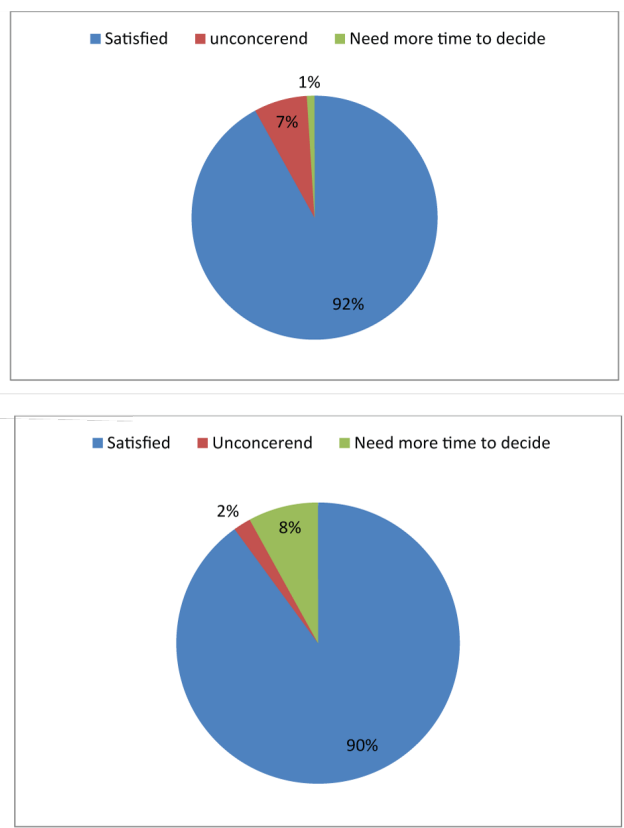

Figure 6: (a) Response from occupants of 8 household on the new septic tank (b) responses from the students on the newly designed septic tank.

\section{Conclusions}

The survey showed that the growing population of Calabar South lacks access to good toilet system and the majority of the people in the surveyed area lack access to proper sanitation. As such, they are vulnerable to several diseases. Due to shallow groundwater condition of Calabar South, pit latrines contaminates nearby borehole water and the entire environment. Positive response from the household of 8 occupants and 150 students primary school about the new toilets septic tank designed encouraged the proper implementation of ecological sanitation toilets in the area. Toilet is very important in everyday live. If there is no suitable toilet, people will be unhealthy and the surroundings will be dirty. This is because without clean and adequate toilet system, people will defecate in the bush or open environment and this directly pollutes the river, underground water, and other easily contaminated foods. Awareness and implementation of ecological sanitation toilets system should be carried out for improved household and institutional sanitation in the area.

\section{Acknowledgements}

The authors wish to express their gratitude to the people of Calabar south who voluntarily participated in the survey and provided the opportunity to design a suitable ecological sanitation septic tank, as awareness for healthy environment. This research did not receive any specific grant from funding agencies in the public, commercial, or notfor-profit sectors.

\section{References}

1. Valipour M (2013) Evolution of Irrigation-Equipped Areas as Share of Cultivated Areas. Irrigation \& Drainage Systems Engineering.

2. Valipour M (2015) Handbook of Environmental Engineering Problems. OMICS Group eBooks.

3. Valipour M (2014) Handbook of Drainage Engineering Problems. OMICS Group eBooks.

4. Joint Monitoring Programme for Water Supply and Sanitation, WHO/ UNICEF (2006).

5. WHO/UNICEF JMP. Progress on Sanitation and Drinking Water (2010).

6. Bareh S (2005) Understanding the importance of environmental Education: An examination of I have a clean San Diego: A Local Environmental Nenprofit Org.

7. International Year of Sanitation in Nigeria (2008).

8. WaterAid calculations for Nigeria using methodology from Evaluation of the Costs and Benefits of Water and Sanitation Improvements (2004).

9. DHS WaterAid estimates in selected LGAs (2003).

10. WaterAid National Water Sector Assessment: Nigeria (2006).

11. Nigeria Education MIS, Fed. Min. of Education (2003).

12. Annual Statistical Bulletin (2006).

13. National Rural Water Supply and Sanitation Strategic Framework, Fed. Ministry of Water Resources (2004).

14. Nigeria Housing and Population Census, National Population Commission (2006).

15. The State of the World's Children UNICEF (2007).

16. Angelakis A (2015) Evolution of Water Lifting Devices (Pumps) over the Centuries Worldwide. Water 7: 5031-5060. 